\title{
VERIFICATION OF THE CAUSES OF GLACIA- TIONS AND SEA LEVEL CHANGES USING THE RECORDS OF CALCITE SPELEOTHEMS
}

\author{
Y. SHOPOV ${ }^{1}$, D. STOYKOVA ${ }^{1}$, L. TSANKOV ${ }^{1}$, M. SANABRIA ${ }^{1}$, \\ J. LUNDBERG ${ }^{2}$, L. GEORGIEV ${ }^{1}$, P. FORTI ${ }^{3}$, D. GEORGIEVA ${ }^{1}$ \\ ${ }^{1}$ Faculty of Physics, University of Sofia \\ James Bouchier 5, Sofia 1164, Bulgaria \\ YYShopov@phys.uni-sofia.bg \\ ${ }^{2}$ Geography Dept., Carleton University \\ 1125 Colonel By Drive, Ottawa, Ontario, Canada K1S $5 B 6$ \\ 3 Dept. of Earth Sciences and Environmental Geology \\ University of Bologna, Via Zamboni 67, 40127 Bologna, Italy
}

\begin{abstract}
The luminescence of calcite speleothems displays an exponential dependence on soil temperature unless there is a dense cover of forest over the cave to dampen it. This relationship is determined primarily by the strength of solar visible and infrared radiation. It is suggested that, as a consequence, the microzonal variations of luminescence often found in speleothems can be used as a proxy index of Solar Insolation.

The luminescence solar insolation proxy record of a speleothem from Jewel Cave, South Dakota, USA, was found to display millenial and centennial cycles in the record. It exhibits a rapid increase in solar insolation at $139 \pm 5.5 \mathrm{kyrs}$. This increase precedes that suggested by the Orbital theory by about 10,000 years and is due to superimposition of the most powerful cycle in solar luminosity of 11.5 kyrs, upon the curve of orbital variations. The record from a speleothem in Duhlata Cave, Bulgaria matches that of South Dakota within the limits of dating error, indicating that both of these records (which are 10,000 km apart) measure global solar insolation controls rather than local paleotemperature variations.
\end{abstract}

Keywords: glaciations, sea level, records, speleothems.

\section{Introduction - Theoretical considerations.}

It has been suggested that the theoretical orbital variation curves explain about one half of the signal in the proxy paleotemperature records extracted from published deep sea and polar ice cores (Imbrie et al., 1992, 1993). The unexplained remainder may be due to long-period self-variation in emission from the sun itself (i.e. in solar 
luminosity - SL).

The Orbital Theory makes two basic assumptions:

1) solar luminosity is constant during geological spans of time.

2) the earth behaves as an unvarying solid body independent of its orbital variations.

Recent studies suggest that both of these assumptions may be incorrect. Direct satellite measurements of the solar constant have found that it has varied by as much as $0.4 \%$ during the comparatively brief period of observation and thus might vary much more during geologically significant time spans (Hickey et al., 1981). Increase of the volume of ice and the related changes of sea level during glaciations produces change in the inertial moment of the Earth, resulting in changes in its speed of rotation (Tenchov \& Tenchov, 1993). These changes must affect the amplitude and, possibly, the frequency of the orbital variations. In turn, variations of the orbit may cause some deformation of the solid Earth and redistribution of its ocean masses (Moerner 1976, 1993). As a result, the theoretically calculated orbital curves should be used only as broad qualitative guides to global climate change. For quantitative correlation it is necessary to seek field records of solar insolation because these will also reflect variations of solar luminosity and other possible effects not covered by the orbital theory.

Until recently there have been no quantitative proxy records that could demonstrate the magnitude of variations of solar luminosity over geological timescales. Shopov et al., (1994) have explored one potential type of record. Calcite speleothems (stalagmites, etc) usually display luminescence that is produced by calcium salts of humic and fulvic acids derived from soils above the caves (Shopov 1989; White and Brennan 1989). These acids are released by the decomposition of humic matter. Rates of decomposition depend exponentially upon soil surface temperatures that are determined primarily by solar infrared radiation (Shopov et al., 1994). Therefore, microzonal variations in the luminescence of speleothems can be used as an indirect measure of the solar activity index, SA (Shopov \& Demendjiev, 1990).

\section{Results and discussion.}

We have measured a luminescence solar insolation proxy record in a speleothem, JC11, from Jewel Cave, South Dakota, USA. The record covers the period, 89,300 138,600 years BP, as determined by six TIMS U/Th ages with 2 sigma errors of 0.8 - 5.5 kyrs. Resolution of the luminescence averages one point per 34 years and precision of measurement is better than $1 \%$. There are millenial and centennial cycles in the record. It exhibits a rapid increase in solar insolation at $139 \pm 5.5$ kyrs which is responsible for Termination II (Fig.1), the close of the penultimate global glaciation. This increase precedes that suggested by the orbital theory by about 10,000 years and is due to the most powerful cycle in solar luminosity, that with a duration of 11.5 kyrs, being superimposed upon the curve of orbital variations. The Devil's Hole, 
Nevada, ${ }^{18} \mathrm{O}$ record from a thermal water calcite deposit also suggests that Termination II commenced about $140 \pm 3$ kyrs (Winograd et al., 1992) and it follows the shape of our solar insolation record precisely. The Devil's Hole findings do not disprove the orbital theory, as has been suggested by others, but do support our contention that the contribution of variations in solar luminosity to terrestrial solar insolation curves is being seriously underestimated. Millennial solar luminosity cycles thus can produce climatic variations with intensities comparable to those caused by orbital variations, and operate on earth's climate by the same mechanism.

We have also measured the luminescence solar insolation proxy record in a speleothem from Duhlata Cave, Bulgaria (Fig.1).

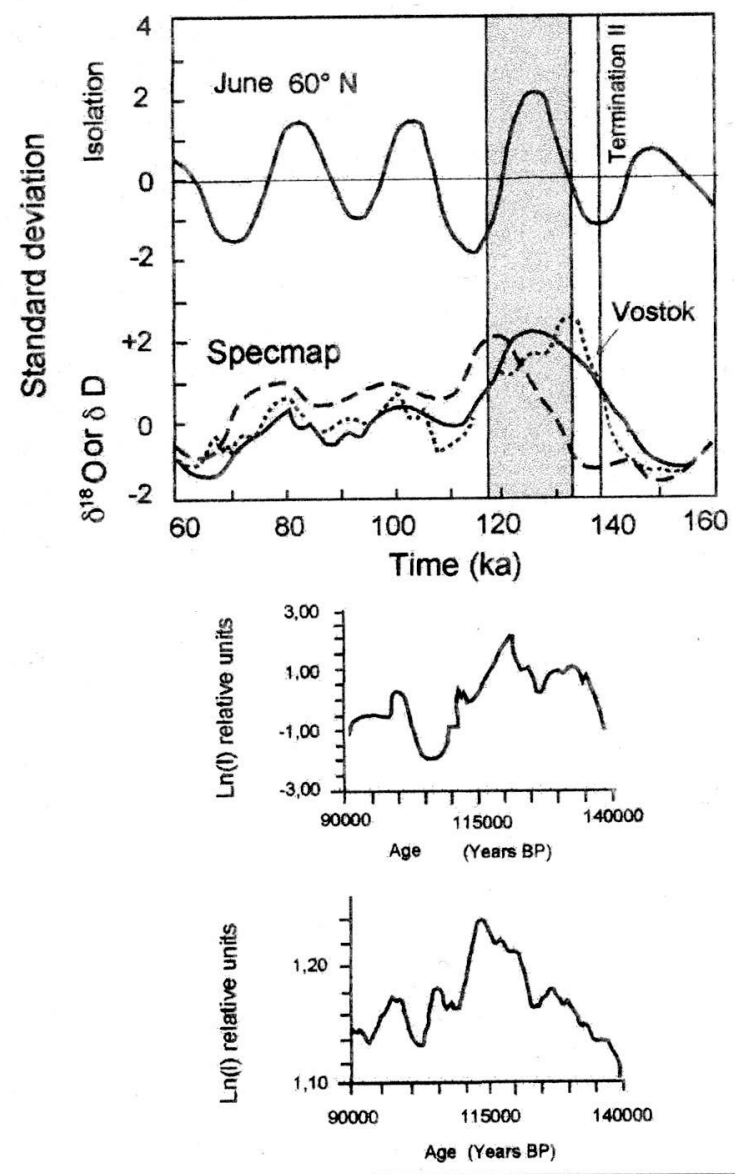

Figure 1-(Upper) The theoretical insolation curve compared to Devils Hole (DH-11), Vostok, and SPECMAP stack stable isotope curves (Winograd et al.,1992). Shading represents high sea level stands (at or above modern levels). (Lower) Jewel Cave (South Dakota) JC11. It is TIMS U/Th dated in 6 points with 2 sigma error varying from 0.8 kyrs (for 89.3 kyrs) to 5.5 kyrs (for 139kyrs). 
It covers the last 250,000 years with a resolution between $250-450$ years and is dated by four TIMS dates. The record matches that of JC11 in South Dakota within the limits of dating error, indicating that both of these records (which are 10,000 km apart) measure global solar insolation controls rather than local paleotemperature variations.

Imbrie, (1985) demonstrated that orbital variations cause major changes of the global sea level because of the melting of the polar ice cap. This author even proposed that units of orbital change be expressed in terms of the resulting changes of sea level; at the last glacial maximum sea level was 120 metres below the modern datum (Fairbanks, 1989). Water and ice strongly adsorb infrared radiation, increasing melting. Lower solar radiation during glaciations permits the build up of major polar ice masses and their extension towards the tropics.

\section{Conclusion.}

Variations of solar luminosity contribute almost as much to changes in the Earth's heating as do the variations of the Earth's orbit around the Sun (Milankovich cycles). The most powerful cycle in luminosity, the $11.5 \mathrm{kyr}$ cycle, was responsible for shifting the onset of the penultimate deglaciation, for example. Almost one half of the total variation in two speleothem records can be attributed to this solar behaviour.

\section{References}

FAIRBANKS R.G., 1989 - A 17,000- year Glacio-eustatic Sea-level Record: Influence of Glacial Melting Rates on the Younger Dry as Event and Deep-ocean Circulation. Nature,342: 637-642.

HICKEY J., ALTON B.,GRIFFIN F., JACOBOVITZ H., PELLEGRINO P., SMITH E., VONDER HAAR T. \& MASCHOFF R., 1981 - Solar variability indications from Nimbus 7 satellite data. In: Variations of the Solar Constant, S.Sofia (Ed.), NASA CP-2191: 59-72.

IMBRIE J., 1985 - A Theoretical Framework for the Pleistocene Ice Ages. J. Geol. Soc. London, 142: 417-432.

IMBRIE J., BOYLE E.A., CLEMENS S.C., DUFFY A., HOWARD W.R., KUKLA G., KUTZBACH J., MARTINSON D., MIX A.C., MOLFINO B., MORLEY J., PETERSON L.C., PISIAS N.G., PRELL W.L., RAYMO M.E., SHACKELTON N.J., TOGGWEILER J.R., 1992 - On the Structure and Origin of Major Glaciation Cycles 1. Linear Responses to Milankovich Forcing. Paleoceanography, 7 (6): 701-736. 
IMBRIE J, BOYLE E.A., CLEMENS S.C., DUFFY A., HOWARD W.R., KUKLA G., KUTZBACH J., MARTINSON D., MIX A.C., MOLFINO B., MORLEY J., PETERSON L.C., PISIAS N.G., PRELL W.L., RAYMO M.E., SHACKELTON N.J., TOGGWEILER J.R., 1993 - On the Structure and Origin of Major Glaciation Cycles 2.The 100,000-year Cycle. Paleoceanography, 8 (6): 669735.

MOERNER N.-A., 1976 - Eustasy and Geoid Changes. J.Geol., 84: 123.

MOERNER N.-A., 1993 - Global Change: the High-amplitude Changes 13-10 ka Ago - Novel Aspects. Global and Planetary Change, 7: 243-250.

SHOPOV Y.Y., 1989 - Spectra of Luminescence of Cave Minerals. Exped. Ann. Univ. Sofia, 3/4: .80- 85 .

SHOPOV Y.Y.,DERMENDJIEV VL., 1990 - Microzonality of Luminescence of Cave Flowstones as a New Indirect Index of Solar Activity. Compt. Rend. Acad. Bulg. Sci., 43 (7): 9-12.

SHOPOV Y.Y.,FORD D.C., SCHWARCZ H.P., 1994 - Luminescent Microbanding in speleothems: High resolution chronology and paleoclimate. Geology, 22: 407 -410 ,

TENCHOV G. G., TENCHOV Y. G., 1993 - An Estimation of Geological Factors Affecting the Long Time Earth Spin Rotation. Compt. Rend. Acad. Bulg. Sci., 46 (12): 37- 40.

WHITE W.B, BRENNAN E.S., 1989 - Luminescence of speleothems due to fulvic acid and other activators. Proc. 10th Int. Congr. Speleology, 13-20 August 1989, Budapest, 1: 212- 214.

WINOGRAD I. J., COPLEN T.B., LANDWEHR J.M., RIGGS A.C., LUDVIG K.R., SZABO B. J., KOLESAR P.T., REVESZ K.M., 1992 - Continuous 500,000-Year Climate Record from Vein Calcite in Devils Hole, Nevada. Science, 258: 255 260 .

Received 14 May 2001

Accepted 29 December 2001 